Document downloaded from:

http://hdl.handle.net/10251/96962

This paper must be cited as:

Capolino, G.; J. Antonino-Daviu; Riera-Guasp, M. (2015). Modern Diagnostics Techniques for Electrical Machines, Power Electronics, and Drives. IEEE Transactions on Industrial Electronics. 62(3):1738-1745. doi:10.1109/TIE.2015.2391186

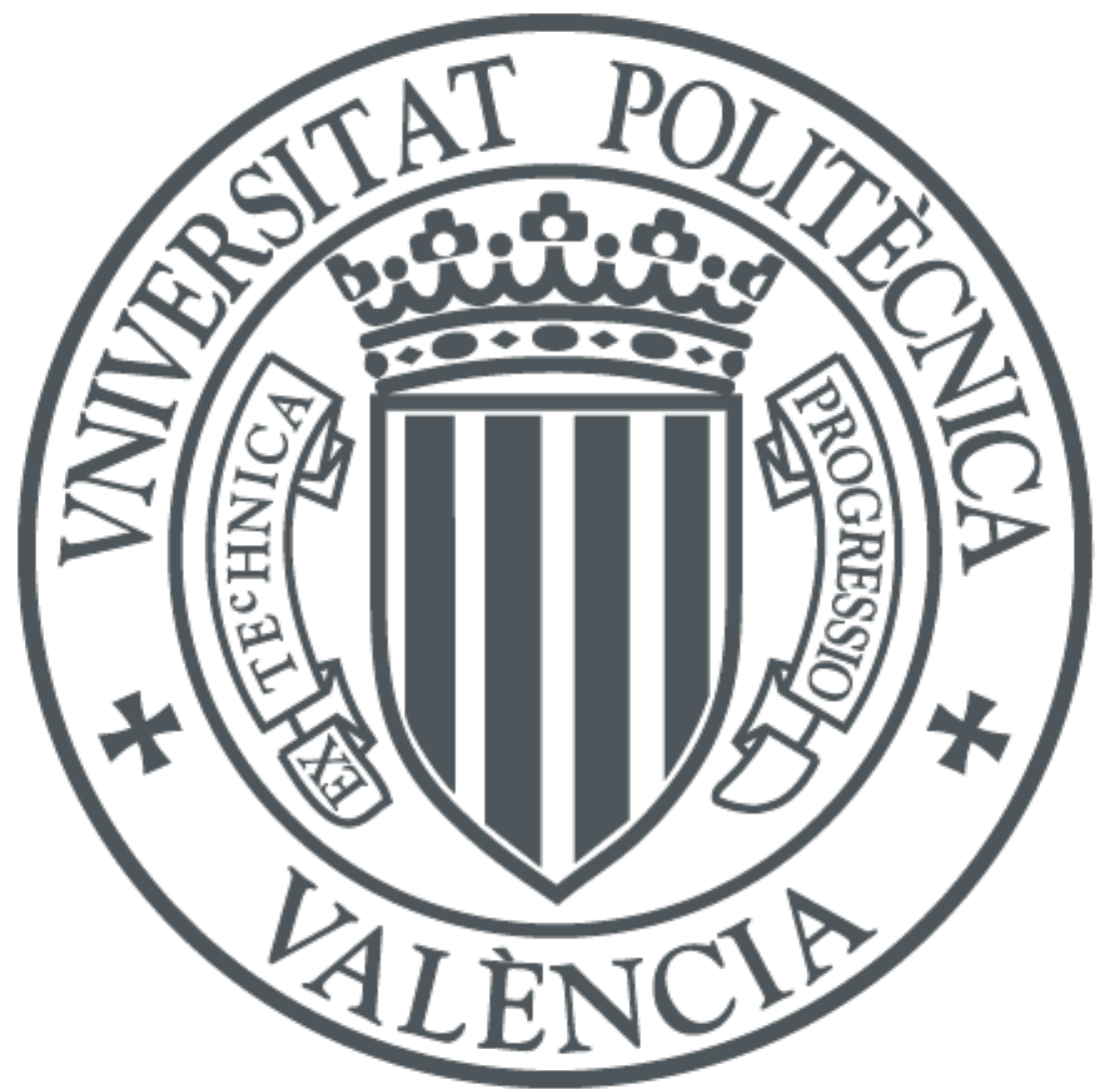

The final publication is available at

http://doi.org/10.1109/TIE.2015.2391186

Copyright Institute of Electrical and Electronics Engineers

Additional Information 


\section{- Modern Diagnostics Techniques for Electrical Machines, Power Electronics, and Drives}

4 OR THE last ten years, at least three different Special 5 Sections dealing with diagnostics in power electrical en6 gineering have been published in the IEEE TRANSACTIONS 7 ON INDUSTRIAL ELECTRONICS [1]-[5]. All of them had their 8 specificities, but the last ones, starting in 2011, were more 9 connected to relevant events organized on the topic. In fact, 10 these events have been clearly the only international forums 11 fully dedicated to diagnostics techniques in power electrical 12 engineering. For this particular issue, it has been decided to 13 separate the different submissions into six parts:

14 - state of the art;

15 - general methods;

16 - induction machines (IMs);

17 - synchronous machines;

18 - electrical drives;

19 - power components and power converters.

20 The second section includes only one state-of-the-art paper, 21 which is dedicated to actual techniques implemented in both 22 industry and research laboratories. The third section includes 23 three papers on diagnostic techniques not specifically aimed at 24 a particular type of machine. The fourth section includes three 25 papers devoted to diagnostics of rotor faults, two dedicated to 26 stator insulation issues, and four papers dealing with mechan27 ical faults diagnosis in IMs. The fifth section includes papers 28 focusing on different types of synchronous machines. The 29 first two papers deal with wound-rotor synchronous machines, 30 the following three papers are dedicated to permanent-magnet 31 radial flux machines, and the last one deals with permanent32 magnet axial flux machines. Regarding the types of faults 33 analyzed, there are three papers devoted to the diagnosis of 34 interturn short circuits in the stator windings, i.e., one dedicated 35 to the detection and location of field-winding-to-ground faults 36 and a paper devoted to the diagnosis of static eccentricities. 37 In the sixth section, two papers investigate issues related to 38 faults in drive sensors, and one is devoted to fault detections 39 in the coupling inductors. The last section includes two papers 40 devoted to diagnosis of faults and losses analysis in switching 41 components of power converters.

\section{2}

\section{StATE OF THE ART}

43 In [6], the authors have screened the most recent papers 44 published on the topic to draw the real "state of the art" on 45 condition monitoring and fault detection of rotating electrical machines, drives, and power electronics. As expected, since 46 it is the most investigated electrical machine from the very 47 beginning, a large part of the development has been dedicated 48 to IMs. It is well known that most of the methods developed 49 for IMs can be simply used directly or adapted for other types 50 of rotating electrical machines or even for linear actuators or 51 generators.

A large part of this paper is dedicated to IM fault detection 53 since it has been the historical field of investigation for the last 54 30 years or so. In this way, rotor faults have been under focus 55 mainly for squirrel-cage IMs with convenient signal processing 56 techniques to tackle the fact that many faults cannot be detected 57 easily when the machine load is light. The second largest part 58 dealing with the IM fault detection is related to stator winding, 59 including the insulation degradation and further early stage 60 short circuits. It has been shown that the insulation degradation 61 detection is the best way to prevent short circuits, but it is 62 the most difficult to be implemented online. Moreover, early 63 stage short circuits are easier to detect particularly by the use 64 of a stray flux sensor, which is simple, cheap, and noninvasive 65 for large-power IMs. Other methods to detect early stage short 66 circuits are based on the impedance asymmetry on the stator 67 side. In this last case, the sensors are based on both stator 68 voltages and stator currents measurements. Then, the decision 69 process for early stage short-circuit detection can be based 70 on advanced artificial intelligence techniques, which are well 71 known in this specific area. Finally, in the case of IMs, methods 72 for mechanical failures detection have been investigated. Faults 73 such as eccentricities, bearings, and gearboxes have been under 74 focus. On the other hand, a brief analysis of the ongoing 75 research in the field of multiphase IMs has been pointed out. $\quad 76$

The same approach has been presented for permanent- 77 magnet synchronous machines (PMSMs) or even synchronous 78 generators (SGs) but with a shorter description since the main 79 features of the IMs fault detection can be applied in the same 80 way for PMSMs. However, the detection of demagnetization 81 has been added as an important point specific to these machines. 82 As in the case of IMs, a brief analysis of the ongoing research 83 in the field of multiphase PMSMs has also been developed. $\quad 84$

The last part of this paper has been dedicated to fault de- 85 tection in power converters and power components as a part 86 of diagnostic techniques associated with power electronics. For 87 the power converters, specific techniques have been developed 88 in order to speed up the detection process in order to avoid 89 components breakage. These techniques have been successfully 90 applied to inverters, matrix converters, and even to dc-dc con- 91 verters. The problem of fault detection in dc link capacitors has 92 also been analyzed. For the power components, things are much 93 more difficult since they have fast switching capabilities and the 94 
95 fault detection has to be as fast as possible. Therefore, the fault 96 detection techniques have been applied to both insulated-gate 97 bipolar transistors (IGBTs) and MOSFETs in order to protect 98 them from irreversible failures. In the same way, the very last 99 part of this paper is dedicated to fault-tolerant drives for which 100 multilevel and multiphase topologies have been developed in 101 the last ten years.

\section{2}

\section{General Methods}

103 In [7], a robust electric motor fault decision-making algo104 rithm, particularly suited for harsh industrial environments, is 105 presented. The proposed technique is based on the simultaneous 106 utilization of multiple fault signature patterns, noise signal fre107 quency patterns, and fundamental harmonics current frequency 108 patterns in a whole motor current signal for diagnosis purposes. 109 As the authors pointed out, the identified pattern is proven to be 110 robust to the signal distortion and inherent monitor noise during 111 motor dynamic operation. In this paper, it is mathematically and 112 experimentally proven that the proposed diagnosis algorithm 113 provides highly accurate monitoring performance while mini114 mizing both false detection and missing detection rates under 115 high noise and nonlinear machine operating conditions. The AQ1 116 experimental results are obtained with a DSP-based IM drive 117 system, where motor control and fault diagnosis are performed 118 in real time. The faulty conditions considered in the work are 119 broken rotor bars and eccentricities. The authors include some 120 comments regarding its possible constraints related to industrial 121 applicability of the proposed technique, stating that since the 122 proposed method assumes prior knowledge of harmonics in 123 a motor current spectrum, small additional memory might be 124 required to implement the proposed method. In addition, a suf125 ficient frequency bandwidth of data acquisition and motor con126 trol is required, particularly for high-frequency signal detection. 127 In [8], a new online diagnosis of three-phase IM stator 128 faults using a signal-based method is proposed. The proposed 129 technique starts with a data preprocessing stage, in which prin130 cipal component analysis (PCA) is applied to current signals. 131 PCA enables the reduction of the three-phase currents space 132 to a two-dimensional space. Afterward, features are extracted 133 from PCA-transformed data using the kernel density estimation 134 (KDE) improved by fast Gaussian transform along with a point 135 reduction method. The automatic fault identification is achieved 136 by means of Kullback-Leibler divergence (KLD), which is used 137 as an index to identify the dissimilarity between two probability 138 distributions. The final goal is to ensure that the developed 139 technique can be used for online monitoring; this is possible due 140 to the remarkable computational cost reduction obtained with 141 the aforementioned enhancement techniques, in comparison 142 with the standard KDE. In this regard, before presenting their 143 developed algorithm, the authors perform a thorough descrip144 tion and analysis of the considered techniques, namely, PCA, $145 \mathrm{KDE}$, improved $\mathrm{KDE}$ by fast Gaussian transform, and point 146 reduction and KLD. This paper also includes experimental 147 results obtained with two different IMs and under three different 148 fault conditions: cracked rotor, out-of-tolerance geometry rotor, 149 and backlash. The tests are carried out at different load and 150 voltage levels to prove the proposed method effectiveness. The authors emphasize that it is totally signal based since no IM 151 parameters are required.

In [9], a stochastic modeling-based prognosis approach 153 [extended Kalman filter (EKF)] is proposed for tracking the 154 remaining useful life (RUL) of bearings under different oper- 155 ating conditions. The proposed data-driven methodology relies 156 on both time and time-frequency domain features of vibration 157 signals obtained from the PROGNOSTIA platform. In this 158 regard, the authors reach original conclusions on the better suit- 159 ability of different features for different operating conditions 160 depending on the length of the test data set. For instance, the 161 authors show that the entropy feature is successful at detecting 162 the early stages of degradation, whereas the variance feature 163 is not very informative until the final failure stage. As the 164 authors point out, shorter test data sets provide less information 165 for RUL estimation yielding higher error rates, which is in 166 concordance with the conclusions of other works based on the 167 same data set. Once features have been extracted, an analytical 168 function, which best approximates the evolution of the fault, 169 is determined and used to learn the parameters of the EKF. In 170 this regard, the work gives a detailed description of the RUL 171 estimation based on EKF, and unlike other investigations, also 172 provides a procedure to estimate the confidence interval along 173 with the RUL estimates. The algorithm is finally applied to 174 bearing vibration data obtained from the mentioned platform, 175 illustrating the convergence of the algorithm, as well as its be- 176 havior under different conditions. The work includes a compar- 177 ison of EKF versus the regular KF showing better performance 178 of the proposed approach for all operating conditions.

IV. IMs

In [10], a detailed comparison between the two main groups 181 of transforms that are employed for IMs rotor assessment based 182 on transient analysis (continuous versus discrete transforms) 183 is presented. In this paper, the discrete wavelet transform and 184 the short-time Fourier transform are taken as representatives 185 of each respective group. The work begins with an overall 186 revision of the diagnosis based on transient analysis and the 187 inherent benefits that such methodology brings in comparison 188 to the conventional motor current signature analysis (MCSA) 189 approach. The authors remark on its usefulness in cases where 190 the MCSA may lead to incorrect diagnostic conclusions. A 191 detailed description of the operation of each group of trans- 192 forms is presented making special emphasis on aspects as 193 fault severity quantification or computational burden. In this 194 regard, the authors emphasize the following advantages of 195 the continuous tools versus their discrete counterparts: clearer 196 extraction of the low-frequency fault components evolutions, 197 possibility of tracking the high-order harmonics evolutions, 198 and easier fault discrimination. Afterward, the authors show 199 the results of applying each transform to data obtained with 200 real IMs. These results do not only consider trivial fault sit- 201 uations, where the conventional MCSA also works well, but 202 also some of the controversial cases, where the application 203 of the conventional methods often leads to false diagnostics, 204 namely, outer bar breakages in double cage IMs, IMs with rotor 205 axial duct influence, as well as combined faults. The authors 206 
207 present a detailed discussion of the performance of each group 208 of transforms based on their results concerning aspects such as 209 quantification or computational time. In their conclusions, they 210 ratify the aforementioned advantages of the continuous tools, 211 and they also tear down the false myth concerning the higher 212 computational burden of continuous transforms.

213 In [11], the authors analyze a diagnostic problem related to 214 IMs with special magnetic structures. More specifically, this 215 paper deals with the false broken rotor bar alarms that have been 216 reported in cage IMs with a number of rotor axial ducts equal to 217 the number of poles. In such cases, even in healthy conditions, 218 two sidebands appear around the fundamental component; their 219 frequencies are equal to those produced by a broken bar. This 220 problem is documented through the analysis of three high221 voltage IMs working in actual industrial applications that were 222 misdiagnosed. The authors analyze the theoretical origin of this 223 issue and conclude that the confusing sidebands are produced 224 by the periodical variations of reluctance that the fundamen225 tal flux wave undergoes during its relative rotation along the 226 cross section of the rotor. Once the physical phenomenon is 227 explained, the authors propose a diagnosis method based on the 228 current sidebands originated by the fifth and seventh space har229 monics of the flux wave. The authors state that these high-order 230 harmonics hardly penetrate the rotor core and, consequently, 231 are not affected by the rotor axial air ducts. This hypothesis is 232 experimentally verified using specifically built prototypes.

233 In [12], the results of a fatigue test that is intended to 234 reproduce, in the most natural way possible, the exposed rotor 235 bar breakage process in an IM. For this purpose, a $1.5-\mathrm{kW}$ 236 two-pole squirrel-cage IM is monitored along 82265 identical 237 working cycles, each one comprising a heavy start-up, a pe238 riod of stationary operation at rated load and, finally, a plug 239 stopping. To accelerate the breakage process, one of the rotor 240 rings was mechanized in order to weaken the junction between 241 the end-ring and the bars. In addition, an incipient breakage 242 was forced in one of the rotor bars. Afterward, the working 243 cycle was repeated until the bar naturally cracked. Taking as 244 bases the results of these tests, the authors carry out three 245 different analyses. First, they compare the performances of sev246 eral fault indicators described in the literature for tracking the 247 fault components evolutions; transient and steady-state-based 248 parameters are considered in this study. Second, an explanation 249 of the breakage mechanism is given, based on a series of 250 pictures of the breakage region, which were taken during the 251 breakage development. Third, a physical model of the failure 252 is introduced and, based on this model, the authors propose 253 an algorithm for state estimation and prognosis analysis of the 254 bars health.

255 In [13], a diagnostic method based on parameter estimation, 256 which is applied to the detection of interturn short circuits in $257 \mathrm{IMs}$, is proposed. The detection algorithm is based on three 258 blocks that are cyclically executed: The first block is a coupled 259 circuits model of the IM, able to simulate faults in the stator 260 windings; in this model, the faults are characterized by three 261 parameters ( $\mu f$ : fault location; $\mu f$ : severity of the fault; LL: 262 load level). The second block is an objective function whose 263 value depends on the errors between the measured currents 264 and the currents calculated by the model. The third block is a global optimization algorithm, called hyperbolic cross points 265 algorithm. It efficiently seeks the combination of parameter 266 values, which minimize the objective function under the tested 267 operation conditions. The authors claim that the proposed al- 268 gorithm reliably locates, with a reduced number of iterations, 269 the global minimum of the objective function, avoiding errors 270 due to local minima. The state of the IM, i.e., the severity and 271 location of the fault, is characterized by the set of parameters 272 that lead to the global minimum of the objective function. The 273 authors validate the method by simulations and laboratory tests, 274 showing that it can detect a fault affecting $8 \%$ of the turns of a 275 phase with a processing time of $106 \mathrm{~s}$.

276

In [14], a method for monitoring the insulation health of 277 IMs is proposed. As the authors highlight, the objective of 278 this work is not to detect sudden insulation faults but to ob- 279 serve a trend of the insulation state indicator over time. The 280 method is applicable to IMs fed by voltage-source inverters. It 281 relies on an offline test, which consists of applying a voltage 282 step, obtained by switching the inverter, to the tested phase. 283 The subsequent reaction current is recorded and employed to 284 evaluate the winding condition. This current is based on high- 285 frequency oscillations, which vanish after a few microseconds. 286 It is shown that the current evolution depends on the parasitic 287 turn-to-turn and winding-to-ground capacitances that change 288 during the aging process of the insulation. The authors propose 289 two insulation state indicators, which are intended for phase 290 evaluation (ISI) and global winding evaluation (SISI). These 291 parameters are computed comparing the current spectra and 292 reference spectra, obtained in healthy condition. The method 293 is validated on two quite different IMs, rated $280 \mathrm{~V}, 5.5 \mathrm{~kW}$ and 294 $1428 \mathrm{~kW}, 2183 \mathrm{~V}$, respectively.

In [15], a new technique based on stray flux measurement is 296 proposed for bearing fault detection in IMs. The method relies 297 on the statistical processing of the measurements of this quan- 298 tity in different positions around the IM. The usefulness of the 299 proposed method is mainly justified based on the simplicity and 300 the flexibility of the custom flux probe with its amplification 301 and filtering stage. The authors first present a detailed literature 302 survey about the use of stray flux measurement in the IMs fault 303 diagnosis area, emphasizing the advantages of such approach 304 in comparison with other techniques. Afterward, their proposed 305 method is described; it requires at least ten data acquisitions of 306 the stray flux, performed under identical conditions, both for 307 the healthy machine (considered as reference) and the same 308 machine having diverse bearing faults. The authors prove the 309 validity of the method in a real IM, considering three different 310 types of bearing failure (crack in the outer race, hole in the 311 outer race, and deformation of the seal) under different load 312 conditions. In addition, different positions for the flux mea- 313 surement with their custom probe are considered, as well as a 314 comparison with a commercial probe, leading to a total number 315 of 32 analyzed cases. Their subsequent discussions lead to 316 interesting conclusions as to the suitability of the method even 317 to detect damages in the bearing seal, the good performance 318 of their probe for higher loads or the general higher effectivity 319 of the custom probe versus the commercial one for stray flux 320 measurements, among others. The only requisite of the method 321 is that it needs an initial data set as "healthy reference" for 322 
323 comparisons to the successive measurements during the IM 324 lifetime.

325 In [16], a methodology for diagnosing localized defects in 326 the outer race of IM bearings is introduced. The method relies 327 on the spectral analysis of the squared envelope of the stator 328 current in an optimized frequency band, characterized by a 329 central frequency $f c$ and a bandwidth $B w$, which contains the 330 nonstationary components with frequencies related to fault. The 331 optimum frequency interval is selected using the kurtogram of 332 the current as a decision tool: it simply consists of selecting the 333 central frequency/bandwidth combination that maximizes the 334 spectral Kurtosis in the kurtogram. Advanced algorithms such 335 as the fast kurtogram or the wavelet kurtogram are used in this 336 work to compute the kurtogram in a computationally efficient 337 way. The method is validated by means of laboratory tests, 338 using two bearings with forced faults, consisting of holes with 339 different diameters. Under these strong defect conditions, this 340 technique enables a clear detection of the fault components, 341 although as the authors state, the method needs to be validated 342 with small and real defects.

343 In [17], the authors have presented the gear tooth damage 344 fault detection using the IM as a sensor but measuring its stator 345 currents. The basic principle is to use the torque oscillations 346 as a means to bring to the IM currents the image of what is 347 happening in the mechanical part related to the machine shaft. 348 Therefore, the electromagnetic torque has been developed as 349 a mean part plus an oscillation part for both healthy and faulty 350 cases and characteristic frequencies of the oscillating parts 351 have been identified. A simplified model of the mechanical part 352 has been developed to compute these characteristic frequencies 353 from a theoretical point of view and to relate them to the IM 354 currents. In order to detect the different frequencies related to 355 the mechanical failure, a fault profile reconstruction has been 356 defined and a fault index has been proposed. The proposed 357 methodology has been applied to a simple test rig with a 358 three-phase IM connected by its shaft to a pinion and a wheel 359 with very small surface wear damage on one tooth for each 360 part. Both simulation and experimental results have confirmed 361 the validity of this new technique of mechanical fault detection. 362 In [18], a method called spectral kurtosis with reference is 363 employed to design a system's healthy reference. This approach 364 is afterward evaluated for mechanical unbalance detection in 365 IMs using the stator currents instantaneous frequency. As the 366 authors explain, the definition of a healthy reference enables 367 the computation of normalized fault indicators whose values 368 are independent of the system characteristics. This means a 369 significant advantage when diagnosing systems with different 370 power, coupling, inertia, and load. In this paper, the authors re371 view the concept of kurtosis and demonstrate its ability to detect 372 outliers within a reference distribution. They introduce a new 373 kurtosis-based indicator, $S K_{R}$, which includes a new reference 374 set, and they prove its ability to generate a system's healthy 375 reference and to detect any drift from it. The authors evaluate 376 this indicator using synthetic signals and also experimentally 377 verify its efficiency when applied to the current instantaneous 378 frequency for the detection of low levels of mechanical unbal379 ance. Their results prove the $S K_{R}$ detection capacity with a 380 single fault threshold for a wide range of load conditions and ratify the usefulness of creating a system's healthy reference for 381 the robust detection of weak mechanical unbalances, avoiding 382 false alarms for different operating conditions and showing a 383 great robustness against load variations.

\section{SYNCHRONOUS MACHINES}

In [19], an SG model that enables the simulation of stator 386 interturn short circuits is presented. The novelty of this work is 387 that it develops a hybrid model, in which the Winding Function 388 Approach (WFA) is combined with the $d q 0$ transform. As the 389 authors remark, the proposed model takes advantage of the 390 suitability of WFA for detailed and simple representation of 391 the faults and, at the same time, enables the calculation simplic- 392 ity that is provided by the $d q 0$ representation. Consequently, a 393 very precise model that is suitable to run online is achieved. In 394 addition, this model accounts for the effect of local saturation of 395 the magnetic circuit due to the fault currents. Local saturation 396 and saliency are taken into consideration through a modified 397 airgap function, which facilitates the accurate computation of 398 the inductance of the shorted turns. The model is extensively 399 validated by laboratory tests and compared with a model based 400 on the $d q 0$ transform. The authors conclude that the proposed 401 model provides more accurate results than the $d q 0$ model 402 although its performance with incipient faults needs to be 403 improved.

The work presented in [20] deals with the accurate local- 405 ization of field-winding to ground faults in SGs. First, the 406 authors analyze in detail a previously developed method for 407 the online detection of excitation-system faults to ground that 408 is valid for generators with static excitation. The method allows 409 discriminating if the fault takes place in the ac side or in the dc 410 side of the excitation system. In the event of faults in the dc side, 411 the method approximately forecasts the location of the fault in 412 the excitation winding. However, this procedure depends on the 413 value of the fault resistance $R_{f}$, which has to be estimated; this 414 fact leading to a wide margin of indetermination. The main 415 contribution of this work is a new algorithm that, from the 416 measured quantities, accurately calculates the value of the fault 417 resistance $R_{f}$. The method is validated through laboratory tests 418 and also on a 106-MW SG operating under real conditions in 419 a hydroelectric power plant. From the test results, the authors 420 claim that the proposed method for the computation of $R_{f} 421$ significantly reduces the errors in the fault location; this fact is 422 relevant in hydrogenerators with high number of poles, since it 423 reliably enables the location of the pole where the fault occurs. 424 This way, the extraction of the whole rotor can be avoided, thus 425 substantially reducing repair costs.

In [21], the authors introduce an approach for interturn short- 427 circuit diagnosis in five-phase PMSMs. The approach relies on 428 the spectral analysis of the modulus of a space vector $D^{\rightarrow}$. This 429 vector is obtained as a combination of two space vectors that 430 are calculated from the measured phase voltages but using two 431 different reference frames, named $\alpha \beta$ and $\alpha 2 \beta 2$. It is justified 432 that an interturn fault in one of the stator phases produces an 433 increase in the $D C$ and $2 f s$ components in the spectrum of 434 the modulus of the space vector $D \rightarrow$ ( $f s$ : supply frequency 435 
437 that this signature is very sensible, reaching amplitude incre438 ments in the fault-related harmonics higher than $15 \mathrm{~dB}$ for 439 a fault affecting up to $3 \%$ of the turns of a phase; and it is 440 also clearly different from the signatures produced by other 441 kind of faults (as static or dynamic eccentricity and partial 442 demagnetization), thus enabling a robust and reliable diagnosis 443 of interturn short-circuit faults.

444 The work presented in [22], as in the previous paper, deals 445 with interturn short-circuit detection in PMSMs. In this case, 446 the work is focused on three-phase PMSMs working under 447 high variable load and speed conditions, as it happens in 448 aircraft applications. This work proposes an approach based on 449 parameter identification. The authors introduce a PMSM model 450 based on the $d q$ reference frame, where the short-circuited turns 451 ratios of each phase $\left(n_{s / c A}, n_{s / c B}, n_{s / c C}\right)$ are the parameters 452 to be identified. The estimation of these parameters is carried 453 out using the EKF, which is justified to be a suitable tool that 454 enables to perform accurate estimations in real time, even under 455 continuous and substantial changes in the operation conditions. 456 Finally, the fault indicators are defined as the average value 457 of the estimated short-circuited turns ratios calculated over a 458 sliding window with a length equal to half period of the main 459 component. The approach is extensively validated by simula460 tion and laboratory tests; it is demonstrated to be robust against 461 frequency variations, load variations, power factor variations, 462 load unbalances, and harmonic content variations.

463 Reference [23] is the only paper in this Special Section 464 dealing with axial flux PMSMs. In this paper, the authors 465 introduce a method for diagnosing static eccentricities in axial 466 flux PMSMs. The method requires the installation of three 467 search coils, mounted on three stator teeth shifted $120^{\circ}$. First, 468 a parameter named static eccentricity factor (SEF) is defined 469 in order to characterize the fault severity in such type of 470 machines; then, a simple algorithm is theoretically justified 471 that enables calculation of the SEF, and also the position of 472 minimum airgap in a faulty machine, using the measured back 473 electromotive forces in the search coils. It is interesting that 474 the computed SEF depends neither on the rotor speed nor on 475 the load. The approach is extensively validated via simulations, 476 using a 3-D finite-element software, as well as thorough labo477 ratory tests.

\section{Electrical DRIVES}

479 In [24], a new fault detection and isolation technique is pre480 sented with the aim of making the traditional vector-controlled 481 IM drive fault tolerant against current and speed sensor failure. 482 The underlying idea is that the controller keeps estimating 483 the different currents and the speed and, in case of a fault, it 484 switches to the correct estimated value. On the one hand, the 485 proposed technique extracts eight estimates of currents in the $486 \alpha-\beta$ reference frame (the authors obtain four estimates using 487 the reverse transformation from $d-q$ to $\alpha-\beta$ and the other 488 four using the forward transformation from $a-b-c$ to $\alpha-\beta$ ). 489 In this context, the concept of vector rotation is introduced to 490 decide the correct estimated value of current corresponding to a 491 fault. On the other hand, the speed is estimated by modifying 492 one of the available model reference adaptive system-based formulations (X-based MRAS). Both simulations, as well as 493 experiments carried out with a laboratory prototype, demon- 494 strate that the system is capable of detecting a fault and recon- 495 figure itself in a seamless manner. In this regard, the authors 496 thoroughly evaluate the performance of the proposed algorithm 497 under different faulty conditions of the considered sensors. 498 The results prove that proposed technique works well even in 499 the case of multiple sensor failures and does not require any 500 additional sensor. The developed fault-tolerant controller can 501 be particularly useful for applications such as electric vehicles 502 to avoid complete shutdown of the system, in case of sensor 503 failure.

In [25], the detection of incipient faults in coupling inductors 505 used in three-phase adjustable-speed drives with direct power 506 control-based active front-end rectifiers is considered. More 507 specifically, the authors develop a new strategy for early fault 508 detection in coupling inductors, which enables a fast identi- 509 fication of the defective phase while providing an accurate 510 estimation of the inductance value of the coupling inductors that 511 enhances the performance of the direct power control method. 512 The underlying idea is that coupling inductor faults (e.g., an 513 interturn short circuit) lead to a variation in the value of the 514 coupling inductance. Hence, the goal is to detect the fault by 515 tracking estimations of the coupling inductances associated 516 with a fault in each phase. A detailed description of the full 517 estimation procedure is given in this paper. Both simulation 518 and experimental tests demonstrate the validity of the proposed 519 method. As stated in this paper, the detection of the fault 520 enables the suspension of the service if this is required to 521 avoid a major breakdown. In addition, the identification of the 522 affected phase enables the replacement of only the defective 523 inductor if three single-phase chokes are used or helps with 524 the repair of the nonhealthy winding if a three-phase reactor is 525 used. Among the claimed advantages of the proposed method 526 are the simplicity, speed, and effectiveness. On the other hand, 527 the main constraint relies on the manufacturing tolerance of 528 the inductors, which makes their actual values differ from 529 each other including when there are not any faults. This latter 530 issue, however, does not affect the robustness of the presented 531 strategy.

532

In [26], an observer-based fault detection method is designed 533 for the rotor position sensor of PMSM drives in an elec- 534 tromechanical brake (EMB). To this end, the authors develop 535 a position estimation algorithm with a full-order Luenberger 536 observer for the rotor flux linkage. However, there are some 537 deviations between the observer and the real process caused by 538 model uncertainties and parameter variations. To overcome this 539 drawback, the authors add a crucial feature in their detection 540 method that relies on an adaptive threshold; this is determined 541 by analyzing position estimation errors of the observer. The 542 adaptive threshold enables, among other things, avoidance of 543 missing or false alarms. The experimental results using the 544 EMB test bench prove the effectiveness and robustness of the 545 designed method that can even detect a small amount of phase 546 shift fault within a wide operation range, not only at steady state 547 but also under transient operation. Moreover, the fault-tolerance 548 capability of the proposed method is achieved by introducing a 549 compensation algorithm for the phase shift. The experimental 550 
551 results show that this compensation algorithm is useful for 552 tolerating the phase shift fault. For other types of rotor position 553 sensor faults, the authors propose potential solutions that can 554 overcome low-speed limitation issues, such as the incorporation 555 with a high-frequency injection-based method. This latter ap556 proach can be somehow complementary to that proposed in the 557 work, since each of them shows special suitability for different 558 speed ranges.

\section{VII. Power Components And Power Converters}

560 In [27], an adaptive threshold-based approach is also pre561 sented, but in this case it is to design an electronic failure detec562 tion system applied to the IGBT. More specifically, the method 563 proposed by the authors relies on the direct measurement of 564 behavior of the gate signal during the IGBT turn-on transient 565 via continuous processing using analog and digital electronics. 566 The main goal pursued with an early fault detection design in 567 the IGBT is to obtain a corrective action to prevent propagation 568 of the fault to the complementary device in the same affected 569 leg in the inverter-motor system, when a short circuit or an 570 overcurrent occurs. Two different faults are considered in the 571 work: open-circuit and short-circuit failures. The considered 572 stages of the developed diagnosis scheme are improved resid573 ual generation stage, ramp rate, and a symmetrical adaptable 574 thresholds stage. The final scheme is intended to decrease the 575 false alarm rate by the aforementioned failures. To achieve the 576 early fault detection, the proposed circuit is implemented in 577 the gate driver using analog electronics. As the authors point 578 out, the main advantage of adding detection process with adap579 tive threshold is that the false alarm rate decreases because the 580 system is not so vulnerable to variations in the power supply 581 of the IGBT gate driver circuit. On the other hand, the main 582 limitation is that the proposed design is not suitable for power 583 applications, where the switching frequency is above $20 \mathrm{kHz}$ 584 since the introduction of an external resistance limits the IGBT 585 switching speed.

586 In [28], a methodology to analyze the losses in the converters 587 of fault-tolerant drives is presented. This work aims to evaluate 588 the losses in the power components of the converter (IGBT, 589 diodes, capacitors) during the time the fault takes place, during 590 the subsequent reconfiguration process and, finally, during the 591 operation in faulty mode; the objective is to assess whether the 592 drive components are able to withstand the thermal stresses that 593 produce transient currents during the fault and reconfiguration 594 period; and also assess the possible reduction in the rated power 595 of the converter when operating in faulty mode. The authors 596 perform the analysis on a single but actual topology of a fault597 tolerant inverter and develop a simple model to assess the 598 losses in all the components after an IGBT open-circuit fault 599 event, both during the fault, reconfiguration process, and faulty 600 operation. The model was validated experimentally by compar601 ing the sum of computed losses and the total losses measured 602 in the experimental rig. From the analysis, conclusions about 603 the maximum allowable time in faulty and reconfiguration 604 conditions or the maximum power after the reconfiguration are 605 discussed.

\section{ACKNOWLEDGMENT}

606

The authors would like to thank the journal Editor-in-Chief, 607 Prof. Carlo Cecati, for having accepted their Special Session 608 proposal and for letting them led the process with confidence up 609 to its end. The authors also thank Sandra McLain, the journal 610 administrator, for her timely help anytime it was necessary 611 during both the reviewing process and the editorial conclusion. 612

$\begin{array}{ll}\text { GÉRARD-ANDRÉ CAPOLINO, Guest Editor } & 613 \\ \text { Department of Electrical Engineering } & 614 \\ \text { University of Picardie "Jules Verne" } & 615 \\ \text { 80000 Amiens, France } & 616 \\ \text { JOSE A. ANTONINO-DAVIU, Guest Editor } & 617 \\ \text { Instituto de Ingeniería Energética } & 618 \\ \text { Polytechnic University of Valencia } & 619 \\ \text { 46071 Valencia, Spain } & 620 \\ \text { MARTIN RIERA-GUASP, Guest Editor } & 621 \\ \text { Instituto de Ingeniería Energética } & 622 \\ \text { Polytechnic University of Valencia } & 623 \\ \text { 46071 Valencia, Spain } & 624\end{array}$

REFERENCES

625

[1] A. Bellini and F. Filippetti, "Guest editorial, special section on 626 diagnostics-Part I," IEEE Trans. Ind. Electron., vol. 55, no. 12, 627 pp. 4106-4108, Dec. 2008.

628

2] A. Bellini and F. Filippetti, "Guest editorial, special section on 629 diagnostics-Part II," IEEE Trans. Ind. Electron., vol. 56, no. 11, 630 pp. 4532-4533, Nov. 2009.

[3] G.-A. Capolino and H. Henao, "Guest editorial on diagnostics of electrical 632 machines, power electronics and drives," IEEE Trans. Ind. Electron., 633 vol. 58, no. 5, pp. 1463-1467, May 2011.

[4] G.-A. Capolino and F. Filippetti, "Introduction to the special section 635 on advances in diagnosis for electrical machines, power electronics, 636 drives-Part I," IEEE Trans. Ind. Electron., vol. 60, no. 8, pp. 3396-3397, 637 Aug. 2013.

[5] G.-A. Capolino and F. Filippetti, "Introduction to the special section 639 on advances in diagnosis for electrical machines, power electronics, 640 drives-Part II," IEEE Trans. Ind. Electron., vol. 60, no. 9, pp. 4009- 641 4011, Sep. 2013.

[6] M. Riera-Guasp, J. A. Antonino-Daviu, and G.-A. Capolino, "Advances in 643 electrical machine, power electronic and drive condition monitoring and 644 fault detection: State of the art," IEEE Trans. Ind. Electron., vol. 62, no. 3, 645 Mar. 2015.

[7] S. Choi, E. Pazouki, J. Baek, and H. R. Bahrami, "Iterative condition mon- 647 itoring and fault diagnosis scheme of electric motor for harsh industrial 648 application," IEEE Trans. Ind. Electron., vol. 62, no. 3, Mar. 2015.

[8] A. Giantomassi, F. Ferracuti, S. Iarlori, G. Ippoliti, and S. Longhi, "Elec- 650 tric motor fault detection and diagnosis by kernel density estimation 651 and Kullback-Leibler divergence based on stator current measurements," 652 IEEE Trans. Ind. Electron., vol. 62, no. 3, Mar. 2015.

[9] R. K. Singleton, II, E. G. Strangas, and S. Aviyente, "Extended Kalman 654 filtering for remaining-useful-life estimation of bearings," IEEE Trans. 655 Ind. Electron., vol. 62, no. 3, Mar. 2015.

[10] J. Pons-Llinares et al., "Advanced induction motor rotor fault diagno- 657 sis via continuous and discrete time-frequency tools," IEEE Trans. Ind. 658 Electron., vol. 62, no. 3, Mar. 2015.

659

[11] C. Yang et al., "Screening of false induction motor fault alarms produced 660 by axial air ducts based on the space-harmonic-induced current compo- 661 nents," IEEE Trans. Ind. Electron., vol. 62, no. 3, Mar. 2015.

[12] V. Climente-Alarcon, J. A. Antonino-Daviu, E. G. Strangas, and 663 M. Riera-Guasp, "Rotor-bar breakage mechanism and prognosis in 664 an induction motor," IEEE Trans. Ind. Electron., vol. 62, no. 3, 665 Mar. 2015.

[13] F. Duan and R. Živanović, "Condition monitoring of an induction motor 667 stator windings via global optimization based on the hyperbolic cross 668 points," IEEE Trans. Ind. Electron., vol. 62, no. 3, Mar. 2015. 
670 [14] P. Nussbaumer, M. A. Vogelsberger, and T. M. Wolbank, "Induction 671 machine insulation health state monitoring based on online switch672 ing transient exploitation," IEEE Trans. Ind. Electron., vol. 62, no. 3, 673 Mar. 2015

674 [15] L. Frosini, C. Harlişca, and L. Szabó, "Induction machine bearing faults 675 detection by means of statistical processing of the stray flux measure676 ment," IEEE Trans. Ind. Electron., vol. 62, no. 3, Mar. 2015.

677 [16] V. C. M. N. Leite et al., "Detection of localized bearing faults in induction 678 machines by spectral kurtosis and envelope analysis of stator current," 679 IEEE Trans. Ind. Electron., vol. 62, no. 3, Mar. 2015.

680 [17] S. Hedayati Kia, H. Henao, and G.-A. Capolino, "Gear tooth sur681 face damage fault detection using induction machine stator current 682 space vector analysis," IEEE Trans. Ind. Electron., vol. 62, no. 3, 683 Mar. 2015.

684 [18] E. Fournier et al., "Current-based detection of mechanical unbalance in fault detection in permanent-magnet multiphase machines," IEEE Trans. 697 Ind. Electron., vol. 62, no. 3, Mar. 2015.

[22] B. Aubert, J. Régnier, S. Caux, and D. Alejo, "Kalman-filter-based in- 699 dicator for online interturn short circuits detection in permanent-magnet 700 synchronous generators," IEEE Trans. Ind. Electron., vol. 62, no. 3, 701 Mar. 2015

[23] S. M. Mirimani, A. Vahedi, F. Marignetti, and R. Di Stefano, "An online 703 method for static eccentricity fault detection in axial flux machines," IEEE 704 Trans. Ind. Electron., vol. 62, no. 3, Mar. 2015.

705

[24] C. Chakraborty and V. Verma, "Speed and current sensor fault detection 706 and isolation technique for induction motor drive using axes transforma- 707 tion," IEEE Trans. Ind. Electron., vol. 62, no. 3, Mar. 2015.

[25] J. G. Norniella et al., "Coupling inductor fault detection and estimation 709 in three-phase adjustable-speed drives with direct power control-based 710 active front-end rectifiers," IEEE Trans. Ind. Electron., vol. 62, no. 3, 711 Mar. 2015.

[26] C. Choi, K. Lee, and W. Lee, "Observer-based phase-shift fault detection 713 using adaptive threshold for rotor position sensor of permanent-magnet 714 synchronous machine drives in electromechanical brake," IEEE Trans. 715 Ind. Electron., vol. 62, no. 3, Mar. 2015.

716

[27] M. A. Rodríguez-Blanco et al., "Fault detection for IGBT using adap- 717 tive thresholds during the turn-on transient," IEEE Trans. Ind. Electron., 718 vol. 62, no. 3, Mar. 2015.

[28] A. Stabile, J. O. Estima, C. Boccaletti, and A. J. Marques Cardoso, 720 "Converter power loss analysis in a fault-tolerant permanent-magnet 721 synchronous motor drive," IEEE Trans. Ind. Electron., vol. 62, no. 3, 722 Mar. 2015.

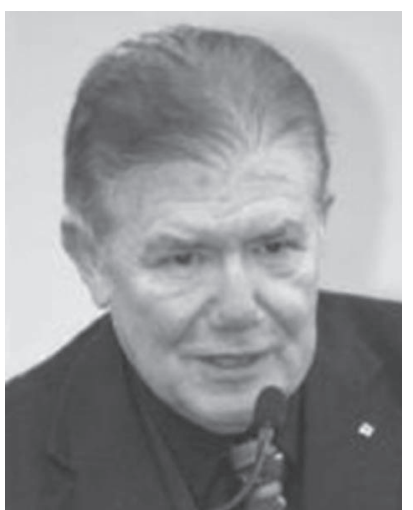

Gérard-André Capolino (A'77-M'82-SM'89-F'02) was born in Marseille, France. He 724 received the B.Sc. degree in electrical engineering from the Ecole Centrale de Marseille, 725 Marseille, in 1974, the M.Sc. degree from the Ecole Supérieure d'Electricité, Paris, 726 France, in 1975, the Ph.D. degree from the Aix-Marseille University, Marseille, in 1978, 727 and the D.Sc. degree from the Institut Polytechnique de Grenoble, Grenoble, France, 728 in 1987.

In 1994, he joined the University of Picardie "Jules Verne," Amiens, France, where he 730 is currently a Chair Professor of electrical engineering.

Dr. Capolino is an Associate Editor of the IEEE Transactions on POWER ElEC- 732 TRONICS, IEEE TRANSACTIONS ON INDUSTRIAL ELECTRONICS, and IEEE ACCESS. He 733 is also the acting Chair for the Steering Committee of the International Conference on 734 Electrical Machines (ICEM). He was the recipient of the 2008 IEEE-IES Dr.-Ing. Eugene 735 Mittelmann Achievement Award, the 2010 ICEM Arthur Ellison Achievement Award, and 736 the 2011 IEEE-PELS Diagnostics Achievement Award.

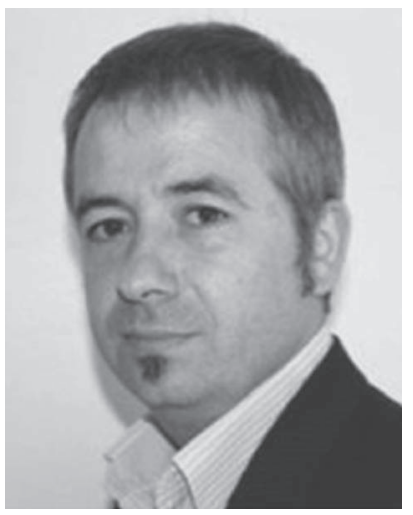

Jose A. Antonino-Daviu (M'06-SM'12) received the M.Sc. and Ph.D. degrees in 738 electrical engineering from the Universitat Politècnica de València, Valencia, Spain, in 739 2000 and 2006, respectively.

He worked in the private sector, having been involved in several international projects. 741 Currently, he is an Associate Professor with the School of Industrial Engineering, 742 Universitat Politècnica de València. His primary research interests include condition 743 monitoring of electric machines, wavelet theory and its application to fault diagnosis, 744 and design and optimization of electrical installations and systems. 


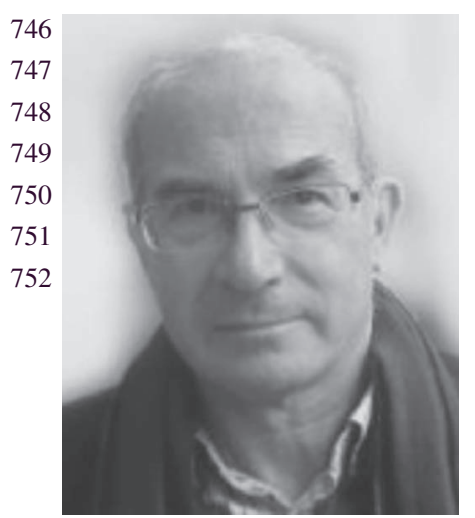

Martin Riera-Guasp (M'94-SM'12) received the M.Sc. degree in industrial engineering and the Ph.D. degree in electrical engineering from the Universitat Politècnica de València, Valencia, Spain, in 1981 and 1987, respectively.

Currently, he is an Associate Professor with the Department of Electrical Engineering, Universitat Politècnica de València. His research interests include condition monitoring of electrical machines, applications of signal analysis techniques to electrical engineering, and efficiency in electric power applications. 


\section{AUTHOR QUERIES}

\section{AUTHOR PLEASE ANSWER ALL QUERIES}

AQ1 = Please check if provided definition for DSP is correct. Otherwise, please make the necessary corrections.

AQ2 = Please check if provided definition for MCSA is correct. Otherwise, please make the necessary corrections.

END OF ALL QUERIES 


\section{- Modern Diagnostics Techniques for Electrical Machines, Power Electronics, and Drives}

47 OR THE last ten years, at least three different Special 5 Sections dealing with diagnostics in power electrical en6 gineering have been published in the IEEE TRANSACTIONS 7 ON INDUSTRIAL ELECTRONICS [1]-[5]. All of them had their 8 specificities, but the last ones, starting in 2011, were more 9 connected to relevant events organized on the topic. In fact, 10 these events have been clearly the only international forums 11 fully dedicated to diagnostics techniques in power electrical 12 engineering. For this particular issue, it has been decided to 13 separate the different submissions into six parts:

14 - state of the art;

15 - general methods;

16 - induction machines (IMs);

17 - synchronous machines;

18 - electrical drives;

19 - power components and power converters.

20 The second section includes only one state-of-the-art paper, 21 which is dedicated to actual techniques implemented in both 22 industry and research laboratories. The third section includes 23 three papers on diagnostic techniques not specifically aimed at 24 a particular type of machine. The fourth section includes three 25 papers devoted to diagnostics of rotor faults, two dedicated to 26 stator insulation issues, and four papers dealing with mechan27 ical faults diagnosis in IMs. The fifth section includes papers 28 focusing on different types of synchronous machines. The 29 first two papers deal with wound-rotor synchronous machines, 30 the following three papers are dedicated to permanent-magnet 31 radial flux machines, and the last one deals with permanent32 magnet axial flux machines. Regarding the types of faults 33 analyzed, there are three papers devoted to the diagnosis of 34 interturn short circuits in the stator windings, i.e., one dedicated 35 to the detection and location of field-winding-to-ground faults 36 and a paper devoted to the diagnosis of static eccentricities. 37 In the sixth section, two papers investigate issues related to 38 faults in drive sensors, and one is devoted to fault detections 39 in the coupling inductors. The last section includes two papers 40 devoted to diagnosis of faults and losses analysis in switching 41 components of power converters.

\section{2}

\section{STATE OF THE ART}

43 In [6], the authors have screened the most recent papers 44 published on the topic to draw the real "state of the art" on 45 condition monitoring and fault detection of rotating electrical

Digital Object Identifier 10.1109/TIE.2015.2391186 machines, drives, and power electronics. As expected, since 46 it is the most investigated electrical machine from the very 47 beginning, a large part of the development has been dedicated 48 to IMs. It is well known that most of the methods developed 49 for IMs can be simply used directly or adapted for other types 50 of rotating electrical machines or even for linear actuators or 51 generators.

A large part of this paper is dedicated to IM fault detection 53 since it has been the historical field of investigation for the last 54 30 years or so. In this way, rotor faults have been under focus 55 mainly for squirrel-cage IMs with convenient signal processing 56 techniques to tackle the fact that many faults cannot be detected 57 easily when the machine load is light. The second largest part 58 dealing with the IM fault detection is related to stator winding, 59 including the insulation degradation and further early stage 60 short circuits. It has been shown that the insulation degradation 61 detection is the best way to prevent short circuits, but it is 62 the most difficult to be implemented online. Moreover, early 63 stage short circuits are easier to detect particularly by the use 64 of a stray flux sensor, which is simple, cheap, and noninvasive 65 for large-power IMs. Other methods to detect early stage short 66 circuits are based on the impedance asymmetry on the stator 67 side. In this last case, the sensors are based on both stator 68 voltages and stator currents measurements. Then, the decision 69 process for early stage short-circuit detection can be based 70 on advanced artificial intelligence techniques, which are well 71 known in this specific area. Finally, in the case of IMs, methods 72 for mechanical failures detection have been investigated. Faults 73 such as eccentricities, bearings, and gearboxes have been under 74 focus. On the other hand, a brief analysis of the ongoing 75 research in the field of multiphase IMs has been pointed out. $\quad 76$

The same approach has been presented for permanent- 77 magnet synchronous machines (PMSMs) or even synchronous 78 generators (SGs) but with a shorter description since the main 79 features of the IMs fault detection can be applied in the same 80 way for PMSMs. However, the detection of demagnetization 81 has been added as an important point specific to these machines. 82 As in the case of IMs, a brief analysis of the ongoing research 83 in the field of multiphase PMSMs has also been developed. $\quad 84$

The last part of this paper has been dedicated to fault de- 85 tection in power converters and power components as a part 86 of diagnostic techniques associated with power electronics. For 87 the power converters, specific techniques have been developed 88 in order to speed up the detection process in order to avoid 89 components breakage. These techniques have been successfully 90 applied to inverters, matrix converters, and even to dc-dc con- 91 verters. The problem of fault detection in dc link capacitors has 92 also been analyzed. For the power components, things are much 93 more difficult since they have fast switching capabilities and the 94 
95 fault detection has to be as fast as possible. Therefore, the fault 96 detection techniques have been applied to both insulated-gate 97 bipolar transistors (IGBTs) and MOSFETs in order to protect 98 them from irreversible failures. In the same way, the very last 99 part of this paper is dedicated to fault-tolerant drives for which 100 multilevel and multiphase topologies have been developed in 101 the last ten years.

\section{2}

\section{General Methods}

103 In [7], a robust electric motor fault decision-making algo104 rithm, particularly suited for harsh industrial environments, is 105 presented. The proposed technique is based on the simultaneous 106 utilization of multiple fault signature patterns, noise signal fre107 quency patterns, and fundamental harmonics current frequency 108 patterns in a whole motor current signal for diagnosis purposes. 109 As the authors pointed out, the identified pattern is proven to be 110 robust to the signal distortion and inherent monitor noise during 111 motor dynamic operation. In this paper, it is mathematically and 112 experimentally proven that the proposed diagnosis algorithm 113 provides highly accurate monitoring performance while mini114 mizing both false detection and missing detection rates under 115 high noise and nonlinear machine operating conditions. The AQ1 116 experimental results are obtained with a DSP-based IM drive 117 system, where motor control and fault diagnosis are performed 118 in real time. The faulty conditions considered in the work are 119 broken rotor bars and eccentricities. The authors include some 120 comments regarding its possible constraints related to industrial 121 applicability of the proposed technique, stating that since the 122 proposed method assumes prior knowledge of harmonics in 123 a motor current spectrum, small additional memory might be 124 required to implement the proposed method. In addition, a suf125 ficient frequency bandwidth of data acquisition and motor con126 trol is required, particularly for high-frequency signal detection. 127 In [8], a new online diagnosis of three-phase IM stator 128 faults using a signal-based method is proposed. The proposed 129 technique starts with a data preprocessing stage, in which prin130 cipal component analysis (PCA) is applied to current signals. 131 PCA enables the reduction of the three-phase currents space 132 to a two-dimensional space. Afterward, features are extracted 133 from PCA-transformed data using the kernel density estimation 134 (KDE) improved by fast Gaussian transform along with a point 135 reduction method. The automatic fault identification is achieved 136 by means of Kullback-Leibler divergence (KLD), which is used 137 as an index to identify the dissimilarity between two probability 138 distributions. The final goal is to ensure that the developed 139 technique can be used for online monitoring; this is possible due 140 to the remarkable computational cost reduction obtained with 141 the aforementioned enhancement techniques, in comparison 142 with the standard KDE. In this regard, before presenting their 143 developed algorithm, the authors perform a thorough descrip144 tion and analysis of the considered techniques, namely, PCA, $145 \mathrm{KDE}$, improved KDE by fast Gaussian transform, and point 146 reduction and KLD. This paper also includes experimental 147 results obtained with two different IMs and under three different 148 fault conditions: cracked rotor, out-of-tolerance geometry rotor, 149 and backlash. The tests are carried out at different load and 150 voltage levels to prove the proposed method effectiveness. The authors emphasize that it is totally signal based since no IM 151 parameters are required.

In [9], a stochastic modeling-based prognosis approach 153 [extended Kalman filter (EKF)] is proposed for tracking the 154 remaining useful life (RUL) of bearings under different oper- 155 ating conditions. The proposed data-driven methodology relies 156 on both time and time-frequency domain features of vibration 157 signals obtained from the PROGNOSTIA platform. In this 158 regard, the authors reach original conclusions on the better suit- 159 ability of different features for different operating conditions 160 depending on the length of the test data set. For instance, the 161 authors show that the entropy feature is successful at detecting 162 the early stages of degradation, whereas the variance feature 163 is not very informative until the final failure stage. As the 164 authors point out, shorter test data sets provide less information 165 for RUL estimation yielding higher error rates, which is in 166 concordance with the conclusions of other works based on the 167 same data set. Once features have been extracted, an analytical 168 function, which best approximates the evolution of the fault, 169 is determined and used to learn the parameters of the EKF. In 170 this regard, the work gives a detailed description of the RUL 171 estimation based on EKF, and unlike other investigations, also 172 provides a procedure to estimate the confidence interval along 173 with the RUL estimates. The algorithm is finally applied to 174 bearing vibration data obtained from the mentioned platform, 175 illustrating the convergence of the algorithm, as well as its be- 176 havior under different conditions. The work includes a compar- 177 ison of EKF versus the regular KF showing better performance 178 of the proposed approach for all operating conditions.

\section{IMs}

In [10], a detailed comparison between the two main groups 181 of transforms that are employed for IMs rotor assessment based 182 on transient analysis (continuous versus discrete transforms) 183 is presented. In this paper, the discrete wavelet transform and 184 the short-time Fourier transform are taken as representatives 185 of each respective group. The work begins with an overall 186 revision of the diagnosis based on transient analysis and the 187 inherent benefits that such methodology brings in comparison 188 to the conventional motor current signature analysis (MCSA) 189 approach. The authors remark on its usefulness in cases where 190 the MCSA may lead to incorrect diagnostic conclusions. A 191 detailed description of the operation of each group of trans- 192 forms is presented making special emphasis on aspects as 193 fault severity quantification or computational burden. In this 194 regard, the authors emphasize the following advantages of 195 the continuous tools versus their discrete counterparts: clearer 196 extraction of the low-frequency fault components evolutions, 197 possibility of tracking the high-order harmonics evolutions, 198 and easier fault discrimination. Afterward, the authors show 199 the results of applying each transform to data obtained with 200 real IMs. These results do not only consider trivial fault sit- 201 uations, where the conventional MCSA also works well, but 202 also some of the controversial cases, where the application 203 of the conventional methods often leads to false diagnostics, 204 namely, outer bar breakages in double cage IMs, IMs with rotor 205 axial duct influence, as well as combined faults. The authors 206 
207 present a detailed discussion of the performance of each group 208 of transforms based on their results concerning aspects such as 209 quantification or computational time. In their conclusions, they 210 ratify the aforementioned advantages of the continuous tools, 211 and they also tear down the false myth concerning the higher 212 computational burden of continuous transforms.

213 In [11], the authors analyze a diagnostic problem related to 214 IMs with special magnetic structures. More specifically, this 215 paper deals with the false broken rotor bar alarms that have been 216 reported in cage IMs with a number of rotor axial ducts equal to 217 the number of poles. In such cases, even in healthy conditions, 218 two sidebands appear around the fundamental component; their 219 frequencies are equal to those produced by a broken bar. This 220 problem is documented through the analysis of three high221 voltage IMs working in actual industrial applications that were 222 misdiagnosed. The authors analyze the theoretical origin of this 223 issue and conclude that the confusing sidebands are produced 224 by the periodical variations of reluctance that the fundamen225 tal flux wave undergoes during its relative rotation along the 226 cross section of the rotor. Once the physical phenomenon is 227 explained, the authors propose a diagnosis method based on the 228 current sidebands originated by the fifth and seventh space har229 monics of the flux wave. The authors state that these high-order 230 harmonics hardly penetrate the rotor core and, consequently, 231 are not affected by the rotor axial air ducts. This hypothesis is 232 experimentally verified using specifically built prototypes.

233 In [12], the results of a fatigue test that is intended to 234 reproduce, in the most natural way possible, the exposed rotor 235 bar breakage process in an IM. For this purpose, a $1.5-\mathrm{kW}$ 236 two-pole squirrel-cage IM is monitored along 82265 identical 237 working cycles, each one comprising a heavy start-up, a pe238 riod of stationary operation at rated load and, finally, a plug 239 stopping. To accelerate the breakage process, one of the rotor 240 rings was mechanized in order to weaken the junction between 241 the end-ring and the bars. In addition, an incipient breakage 242 was forced in one of the rotor bars. Afterward, the working 243 cycle was repeated until the bar naturally cracked. Taking as 244 bases the results of these tests, the authors carry out three 245 different analyses. First, they compare the performances of sev246 eral fault indicators described in the literature for tracking the 247 fault components evolutions; transient and steady-state-based 248 parameters are considered in this study. Second, an explanation 249 of the breakage mechanism is given, based on a series of 250 pictures of the breakage region, which were taken during the 251 breakage development. Third, a physical model of the failure 252 is introduced and, based on this model, the authors propose 253 an algorithm for state estimation and prognosis analysis of the 254 bars health.

255 In [13], a diagnostic method based on parameter estimation, 256 which is applied to the detection of interturn short circuits in 257 IMs, is proposed. The detection algorithm is based on three 258 blocks that are cyclically executed: The first block is a coupled 259 circuits model of the IM, able to simulate faults in the stator 260 windings; in this model, the faults are characterized by three 261 parameters ( $\mu f$ : fault location; $\mu f$ : severity of the fault; LL: 262 load level). The second block is an objective function whose 263 value depends on the errors between the measured currents 264 and the currents calculated by the model. The third block is a global optimization algorithm, called hyperbolic cross points 265 algorithm. It efficiently seeks the combination of parameter 266 values, which minimize the objective function under the tested 267 operation conditions. The authors claim that the proposed al- 268 gorithm reliably locates, with a reduced number of iterations, 269 the global minimum of the objective function, avoiding errors 270 due to local minima. The state of the IM, i.e., the severity and 271 location of the fault, is characterized by the set of parameters 272 that lead to the global minimum of the objective function. The 273 authors validate the method by simulations and laboratory tests, 274 showing that it can detect a fault affecting $8 \%$ of the turns of a 275 phase with a processing time of $106 \mathrm{~s}$.

276

In [14], a method for monitoring the insulation health of 277 IMs is proposed. As the authors highlight, the objective of 278 this work is not to detect sudden insulation faults but to ob- 279 serve a trend of the insulation state indicator over time. The 280 method is applicable to IMs fed by voltage-source inverters. It 281 relies on an offline test, which consists of applying a voltage 282 step, obtained by switching the inverter, to the tested phase. 283 The subsequent reaction current is recorded and employed to 284 evaluate the winding condition. This current is based on high- 285 frequency oscillations, which vanish after a few microseconds. 286 It is shown that the current evolution depends on the parasitic 287 turn-to-turn and winding-to-ground capacitances that change 288 during the aging process of the insulation. The authors propose 289 two insulation state indicators, which are intended for phase 290 evaluation (ISI) and global winding evaluation (SISI). These 291 parameters are computed comparing the current spectra and 292 reference spectra, obtained in healthy condition. The method 293 is validated on two quite different IMs, rated $280 \mathrm{~V}, 5.5 \mathrm{~kW}$ and 294 $1428 \mathrm{~kW}, 2183 \mathrm{~V}$, respectively.

In [15], a new technique based on stray flux measurement is 296 proposed for bearing fault detection in IMs. The method relies 297 on the statistical processing of the measurements of this quan- 298 tity in different positions around the IM. The usefulness of the 299 proposed method is mainly justified based on the simplicity and 300 the flexibility of the custom flux probe with its amplification 301 and filtering stage. The authors first present a detailed literature 302 survey about the use of stray flux measurement in the IMs fault 303 diagnosis area, emphasizing the advantages of such approach 304 in comparison with other techniques. Afterward, their proposed 305 method is described; it requires at least ten data acquisitions of 306 the stray flux, performed under identical conditions, both for 307 the healthy machine (considered as reference) and the same 308 machine having diverse bearing faults. The authors prove the 309 validity of the method in a real IM, considering three different 310 types of bearing failure (crack in the outer race, hole in the 311 outer race, and deformation of the seal) under different load 312 conditions. In addition, different positions for the flux mea- 313 surement with their custom probe are considered, as well as a 314 comparison with a commercial probe, leading to a total number 315 of 32 analyzed cases. Their subsequent discussions lead to 316 interesting conclusions as to the suitability of the method even 317 to detect damages in the bearing seal, the good performance 318 of their probe for higher loads or the general higher effectivity 319 of the custom probe versus the commercial one for stray flux 320 measurements, among others. The only requisite of the method 321 is that it needs an initial data set as "healthy reference" for 322 
323 comparisons to the successive measurements during the IM 324 lifetime.

325 In [16], a methodology for diagnosing localized defects in 326 the outer race of IM bearings is introduced. The method relies 327 on the spectral analysis of the squared envelope of the stator 328 current in an optimized frequency band, characterized by a 329 central frequency $f c$ and a bandwidth $B w$, which contains the 330 nonstationary components with frequencies related to fault. The 331 optimum frequency interval is selected using the kurtogram of 332 the current as a decision tool: it simply consists of selecting the 333 central frequency/bandwidth combination that maximizes the 334 spectral Kurtosis in the kurtogram. Advanced algorithms such 335 as the fast kurtogram or the wavelet kurtogram are used in this 336 work to compute the kurtogram in a computationally efficient 337 way. The method is validated by means of laboratory tests, 338 using two bearings with forced faults, consisting of holes with 339 different diameters. Under these strong defect conditions, this 340 technique enables a clear detection of the fault components, 341 although as the authors state, the method needs to be validated 342 with small and real defects.

343 In [17], the authors have presented the gear tooth damage 344 fault detection using the IM as a sensor but measuring its stator 345 currents. The basic principle is to use the torque oscillations 346 as a means to bring to the IM currents the image of what is 347 happening in the mechanical part related to the machine shaft. 348 Therefore, the electromagnetic torque has been developed as 349 a mean part plus an oscillation part for both healthy and faulty 350 cases and characteristic frequencies of the oscillating parts 351 have been identified. A simplified model of the mechanical part 352 has been developed to compute these characteristic frequencies 353 from a theoretical point of view and to relate them to the IM 354 currents. In order to detect the different frequencies related to 355 the mechanical failure, a fault profile reconstruction has been 356 defined and a fault index has been proposed. The proposed 357 methodology has been applied to a simple test rig with a 358 three-phase IM connected by its shaft to a pinion and a wheel 359 with very small surface wear damage on one tooth for each 360 part. Both simulation and experimental results have confirmed 361 the validity of this new technique of mechanical fault detection. 362 In [18], a method called spectral kurtosis with reference is 363 employed to design a system's healthy reference. This approach 364 is afterward evaluated for mechanical unbalance detection in 365 IMs using the stator currents instantaneous frequency. As the 366 authors explain, the definition of a healthy reference enables 367 the computation of normalized fault indicators whose values 368 are independent of the system characteristics. This means a 369 significant advantage when diagnosing systems with different 370 power, coupling, inertia, and load. In this paper, the authors re371 view the concept of kurtosis and demonstrate its ability to detect 372 outliers within a reference distribution. They introduce a new 373 kurtosis-based indicator, $S K_{R}$, which includes a new reference 374 set, and they prove its ability to generate a system's healthy 375 reference and to detect any drift from it. The authors evaluate 376 this indicator using synthetic signals and also experimentally 377 verify its efficiency when applied to the current instantaneous 378 frequency for the detection of low levels of mechanical unbal379 ance. Their results prove the $S K_{R}$ detection capacity with a 380 single fault threshold for a wide range of load conditions and ratify the usefulness of creating a system's healthy reference for 381 the robust detection of weak mechanical unbalances, avoiding 382 false alarms for different operating conditions and showing a 383 great robustness against load variations.

\section{SYNCHRONOUS MACHINES}

In [19], an SG model that enables the simulation of stator 386 interturn short circuits is presented. The novelty of this work is 387 that it develops a hybrid model, in which the Winding Function 388 Approach (WFA) is combined with the $d q 0$ transform. As the 389 authors remark, the proposed model takes advantage of the 390 suitability of WFA for detailed and simple representation of 391 the faults and, at the same time, enables the calculation simplic- 392 ity that is provided by the $d q 0$ representation. Consequently, a 393 very precise model that is suitable to run online is achieved. In 394 addition, this model accounts for the effect of local saturation of 395 the magnetic circuit due to the fault currents. Local saturation 396 and saliency are taken into consideration through a modified 397 airgap function, which facilitates the accurate computation of 398 the inductance of the shorted turns. The model is extensively 399 validated by laboratory tests and compared with a model based 400 on the $d q 0$ transform. The authors conclude that the proposed 401 model provides more accurate results than the $d q 0$ model 402 although its performance with incipient faults needs to be 403 improved.

404

The work presented in [20] deals with the accurate local- 405 ization of field-winding to ground faults in SGs. First, the 406 authors analyze in detail a previously developed method for 407 the online detection of excitation-system faults to ground that 408 is valid for generators with static excitation. The method allows 409 discriminating if the fault takes place in the ac side or in the dc 410 side of the excitation system. In the event of faults in the dc side, 411 the method approximately forecasts the location of the fault in 412 the excitation winding. However, this procedure depends on the 413 value of the fault resistance $R_{f}$, which has to be estimated; this 414 fact leading to a wide margin of indetermination. The main 415 contribution of this work is a new algorithm that, from the 416 measured quantities, accurately calculates the value of the fault 417 resistance $R_{f}$. The method is validated through laboratory tests 418 and also on a 106-MW SG operating under real conditions in 419 a hydroelectric power plant. From the test results, the authors 420 claim that the proposed method for the computation of $R_{f} 421$ significantly reduces the errors in the fault location; this fact is 422 relevant in hydrogenerators with high number of poles, since it 423 reliably enables the location of the pole where the fault occurs. 424 This way, the extraction of the whole rotor can be avoided, thus 425 substantially reducing repair costs.

In [21], the authors introduce an approach for interturn short- 427 circuit diagnosis in five-phase PMSMs. The approach relies on 428 the spectral analysis of the modulus of a space vector $\vec{D}$. This 429 vector is obtained as a combination of two space vectors that 430 are calculated from the measured phase voltages but using two 431 different reference frames, named $\alpha \beta$ and $\alpha 2 \beta 2$. It is justified 432 that an interturn fault in one of the stator phases produces an 433 increase in the $D C$ and $2 f s$ components in the spectrum of 434 the modulus of the space vector $\vec{D}$ ( $f s$ : supply frequency 435 fundamental harmonic). It is shown from simulations and tests 436 
437 that this signature is very sensible, reaching amplitude incre438 ments in the fault-related harmonics higher than $15 \mathrm{~dB}$ for 439 a fault affecting up to $3 \%$ of the turns of a phase; and it is 440 also clearly different from the signatures produced by other 441 kind of faults (as static or dynamic eccentricity and partial 442 demagnetization), thus enabling a robust and reliable diagnosis 443 of interturn short-circuit faults.

444 The work presented in [22], as in the previous paper, deals 445 with interturn short-circuit detection in PMSMs. In this case, 446 the work is focused on three-phase PMSMs working under 447 high variable load and speed conditions, as it happens in 448 aircraft applications. This work proposes an approach based on 449 parameter identification. The authors introduce a PMSM model 450 based on the $d q$ reference frame, where the short-circuited turns 451 ratios of each phase $\left(n_{s / c A}, n_{s / c B}, n_{s / c C}\right)$ are the parameters 452 to be identified. The estimation of these parameters is carried 453 out using the EKF, which is justified to be a suitable tool that 454 enables to perform accurate estimations in real time, even under 455 continuous and substantial changes in the operation conditions. 456 Finally, the fault indicators are defined as the average value 457 of the estimated short-circuited turns ratios calculated over a 458 sliding window with a length equal to half period of the main 459 component. The approach is extensively validated by simula460 tion and laboratory tests; it is demonstrated to be robust against 461 frequency variations, load variations, power factor variations, 462 load unbalances, and harmonic content variations.

463 Reference [23] is the only paper in this Special Section 464 dealing with axial flux PMSMs. In this paper, the authors 465 introduce a method for diagnosing static eccentricities in axial 466 flux PMSMs. The method requires the installation of three 467 search coils, mounted on three stator teeth shifted $120^{\circ}$. First, 468 a parameter named static eccentricity factor (SEF) is defined 469 in order to characterize the fault severity in such type of 470 machines; then, a simple algorithm is theoretically justified 471 that enables calculation of the SEF, and also the position of 472 minimum airgap in a faulty machine, using the measured back 473 electromotive forces in the search coils. It is interesting that 474 the computed SEF depends neither on the rotor speed nor on 475 the load. The approach is extensively validated via simulations, 476 using a 3-D finite-element software, as well as thorough labo477 ratory tests.

\section{Electrical Drives}

479 In [24], a new fault detection and isolation technique is pre480 sented with the aim of making the traditional vector-controlled 481 IM drive fault tolerant against current and speed sensor failure. 482 The underlying idea is that the controller keeps estimating 483 the different currents and the speed and, in case of a fault, it 484 switches to the correct estimated value. On the one hand, the 485 proposed technique extracts eight estimates of currents in the $486 \alpha-\beta$ reference frame (the authors obtain four estimates using 487 the reverse transformation from $d-q$ to $\alpha-\beta$ and the other 488 four using the forward transformation from $a-b-c$ to $\alpha-\beta$ ). 489 In this context, the concept of vector rotation is introduced to 490 decide the correct estimated value of current corresponding to a 491 fault. On the other hand, the speed is estimated by modifying 492 one of the available model reference adaptive system-based formulations (X-based MRAS). Both simulations, as well as 493 experiments carried out with a laboratory prototype, demon- 494 strate that the system is capable of detecting a fault and recon- 495 figure itself in a seamless manner. In this regard, the authors 496 thoroughly evaluate the performance of the proposed algorithm 497 under different faulty conditions of the considered sensors. 498 The results prove that proposed technique works well even in 499 the case of multiple sensor failures and does not require any 500 additional sensor. The developed fault-tolerant controller can 501 be particularly useful for applications such as electric vehicles 502 to avoid complete shutdown of the system, in case of sensor 503 failure.

In [25], the detection of incipient faults in coupling inductors 505 used in three-phase adjustable-speed drives with direct power 506 control-based active front-end rectifiers is considered. More 507 specifically, the authors develop a new strategy for early fault 508 detection in coupling inductors, which enables a fast identi- 509 fication of the defective phase while providing an accurate 510 estimation of the inductance value of the coupling inductors that 511 enhances the performance of the direct power control method. 512 The underlying idea is that coupling inductor faults (e.g., an 513 interturn short circuit) lead to a variation in the value of the 514 coupling inductance. Hence, the goal is to detect the fault by 515 tracking estimations of the coupling inductances associated 516 with a fault in each phase. A detailed description of the full 517 estimation procedure is given in this paper. Both simulation 518 and experimental tests demonstrate the validity of the proposed 519 method. As stated in this paper, the detection of the fault 520 enables the suspension of the service if this is required to 521 avoid a major breakdown. In addition, the identification of the 522 affected phase enables the replacement of only the defective 523 inductor if three single-phase chokes are used or helps with 524 the repair of the nonhealthy winding if a three-phase reactor is 525 used. Among the claimed advantages of the proposed method 526 are the simplicity, speed, and effectiveness. On the other hand, 527 the main constraint relies on the manufacturing tolerance of 528 the inductors, which makes their actual values differ from 529 each other including when there are not any faults. This latter 530 issue, however, does not affect the robustness of the presented 531 strategy.

532

In [26], an observer-based fault detection method is designed 533 for the rotor position sensor of PMSM drives in an elec- 534 tromechanical brake (EMB). To this end, the authors develop 535 a position estimation algorithm with a full-order Luenberger 536 observer for the rotor flux linkage. However, there are some 537 deviations between the observer and the real process caused by 538 model uncertainties and parameter variations. To overcome this 539 drawback, the authors add a crucial feature in their detection 540 method that relies on an adaptive threshold; this is determined 541 by analyzing position estimation errors of the observer. The 542 adaptive threshold enables, among other things, avoidance of 543 missing or false alarms. The experimental results using the 544 EMB test bench prove the effectiveness and robustness of the 545 designed method that can even detect a small amount of phase 546 shift fault within a wide operation range, not only at steady state 547 but also under transient operation. Moreover, the fault-tolerance 548 capability of the proposed method is achieved by introducing a 549 compensation algorithm for the phase shift. The experimental 550 
551 results show that this compensation algorithm is useful for 552 tolerating the phase shift fault. For other types of rotor position 553 sensor faults, the authors propose potential solutions that can 554 overcome low-speed limitation issues, such as the incorporation 555 with a high-frequency injection-based method. This latter ap556 proach can be somehow complementary to that proposed in the 557 work, since each of them shows special suitability for different 558 speed ranges.

\section{VII. Power Components and Power Converters}

560 In [27], an adaptive threshold-based approach is also pre561 sented, but in this case it is to design an electronic failure detec562 tion system applied to the IGBT. More specifically, the method 563 proposed by the authors relies on the direct measurement of 564 behavior of the gate signal during the IGBT turn-on transient 565 via continuous processing using analog and digital electronics. 566 The main goal pursued with an early fault detection design in 567 the IGBT is to obtain a corrective action to prevent propagation 568 of the fault to the complementary device in the same affected 569 leg in the inverter-motor system, when a short circuit or an 570 overcurrent occurs. Two different faults are considered in the 571 work: open-circuit and short-circuit failures. The considered 572 stages of the developed diagnosis scheme are improved resid573 ual generation stage, ramp rate, and a symmetrical adaptable 574 thresholds stage. The final scheme is intended to decrease the 575 false alarm rate by the aforementioned failures. To achieve the 576 early fault detection, the proposed circuit is implemented in 577 the gate driver using analog electronics. As the authors point 578 out, the main advantage of adding detection process with adap579 tive threshold is that the false alarm rate decreases because the 580 system is not so vulnerable to variations in the power supply 581 of the IGBT gate driver circuit. On the other hand, the main 582 limitation is that the proposed design is not suitable for power 583 applications, where the switching frequency is above $20 \mathrm{kHz}$ 584 since the introduction of an external resistance limits the IGBT 585 switching speed.

586 In [28], a methodology to analyze the losses in the converters 587 of fault-tolerant drives is presented. This work aims to evaluate 588 the losses in the power components of the converter (IGBT, 589 diodes, capacitors) during the time the fault takes place, during 590 the subsequent reconfiguration process and, finally, during the 591 operation in faulty mode; the objective is to assess whether the 592 drive components are able to withstand the thermal stresses that 593 produce transient currents during the fault and reconfiguration 594 period; and also assess the possible reduction in the rated power 595 of the converter when operating in faulty mode. The authors 596 perform the analysis on a single but actual topology of a fault597 tolerant inverter and develop a simple model to assess the 598 losses in all the components after an IGBT open-circuit fault 599 event, both during the fault, reconfiguration process, and faulty 600 operation. The model was validated experimentally by compar601 ing the sum of computed losses and the total losses measured 602 in the experimental rig. From the analysis, conclusions about 603 the maximum allowable time in faulty and reconfiguration 604 conditions or the maximum power after the reconfiguration are 605 discussed.

\section{ACKNOWLEDGMENT}

606

The authors would like to thank the journal Editor-in-Chief, 607 Prof. Carlo Cecati, for having accepted their Special Session 608 proposal and for letting them led the process with confidence up 609 to its end. The authors also thank Sandra McLain, the journal 610 administrator, for her timely help anytime it was necessary 611 during both the reviewing process and the editorial conclusion. 612

$\begin{array}{ll}\text { GÉRARD-ANDRÉ CAPOLINO, Guest Editor } & 613 \\ \text { Department of Electrical Engineering } & 614 \\ \text { University of Picardie "Jules Verne" } & 615 \\ 80000 \text { Amiens, France } & 616 \\ \text { JOSE A. ANTONINO-DAVIU, Guest Editor } & 617 \\ \text { Instituto de Ingeniería Energética } & 618 \\ \text { Polytechnic University of Valencia } & 619 \\ \text { 46071 Valencia, Spain } & 620 \\ \text { MARTIN RIERA-GUASP, Guest Editor } & 621 \\ \text { Instituto de Ingeniería Energética } & 622 \\ \text { Polytechnic University of Valencia } & 623 \\ \text { 46071 Valencia, Spain } & 624 \\ & \\ & \end{array}$

[1] A. Bellini and F. Filippetti, "Guest editorial, special section on 626 diagnostics-Part I," IEEE Trans. Ind. Electron., vol. 55, no. 12, 627 pp. 4106-4108, Dec. 2008.

628

[2] A. Bellini and F. Filippetti, "Guest editorial, special section on 629 diagnostics-Part II," IEEE Trans. Ind. Electron., vol. 56, no. 11, 630 pp. 4532-4533, Nov. 2009.

[3] G.-A. Capolino and H. Henao, "Guest editorial on diagnostics of electrical 632 machines, power electronics and drives," IEEE Trans. Ind. Electron., 633 vol. 58, no. 5, pp. 1463-1467, May 2011.

634

[4] G.-A. Capolino and F. Filippetti, "Introduction to the special section 635 on advances in diagnosis for electrical machines, power electronics, 636 drives-Part I," IEEE Trans. Ind. Electron., vol. 60, no. 8, pp. 3396-3397, 637 Aug. 2013.

[5] G.-A. Capolino and F. Filippetti, "Introduction to the special section 639 on advances in diagnosis for electrical machines, power electronics, 640 drives-Part II," IEEE Trans. Ind. Electron., vol. 60, no. 9, pp. 4009- 641 4011, Sep. 2013.

[6] M. Riera-Guasp, J. A. Antonino-Daviu, and G.-A. Capolino, "Advances in 643 electrical machine, power electronic and drive condition monitoring and 644 fault detection: State of the art," IEEE Trans. Ind. Electron., vol. 62, no. 3, 645 Mar. 2015.

[7] S. Choi, E. Pazouki, J. Baek, and H. R. Bahrami, "Iterative condition mon- 647 itoring and fault diagnosis scheme of electric motor for harsh industrial 648 application," IEEE Trans. Ind. Electron., vol. 62, no. 3, Mar. 2015.

[8] A. Giantomassi, F. Ferracuti, S. Iarlori, G. Ippoliti, and S. Longhi, "Elec- 650 tric motor fault detection and diagnosis by kernel density estimation 651 and Kullback-Leibler divergence based on stator current measurements," 652 IEEE Trans. Ind. Electron., vol. 62, no. 3, Mar. 2015.

[9] R. K. Singleton, II, E. G. Strangas, and S. Aviyente, "Extended Kalman 654 filtering for remaining-useful-life estimation of bearings," IEEE Trans. 655 Ind. Electron., vol. 62, no. 3, Mar. 2015.

[10] J. Pons-Llinares et al., "Advanced induction motor rotor fault diagno- 657 sis via continuous and discrete time-frequency tools," IEEE Trans. Ind. 658 Electron., vol. 62, no. 3, Mar. 2015.

659

[11] C. Yang et al., "Screening of false induction motor fault alarms produced 660 by axial air ducts based on the space-harmonic-induced current compo- 661 nents," IEEE Trans. Ind. Electron., vol. 62, no. 3, Mar. 2015.

[12] V. Climente-Alarcon, J. A. Antonino-Daviu, E. G. Strangas, and 663 M. Riera-Guasp, "Rotor-bar breakage mechanism and prognosis in 664 an induction motor," IEEE Trans. Ind. Electron., vol. 62, no. 3, 665 Mar. 2015.

[13] F. Duan and R. Živanović, "Condition monitoring of an induction motor 667 stator windings via global optimization based on the hyperbolic cross 668 points," IEEE Trans. Ind. Electron., vol. 62, no. 3, Mar. 2015. 
670 [14] P. Nussbaumer, M. A. Vogelsberger, and T. M. Wolbank, "Induction 671 machine insulation health state monitoring based on online switch672 ing transient exploitation," IEEE Trans. Ind. Electron., vol. 62, no. 3, 673 Mar. 2015

674 [15] L. Frosini, C. Harlişca, and L. Szabó, "Induction machine bearing faults 675 detection by means of statistical processing of the stray flux measure676 ment," IEEE Trans. Ind. Electron., vol. 62, no. 3, Mar. 2015

677 [16] V. C. M. N. Leite et al., "Detection of localized bearing faults in induction 678 machines by spectral kurtosis and envelope analysis of stator current," 679 IEEE Trans. Ind. Electron., vol. 62, no. 3, Mar. 2015.

680 [17] S. Hedayati Kia, H. Henao, and G.-A. Capolino, "Gear tooth sur681 face damage fault detection using induction machine stator current 682 space vector analysis," IEEE Trans. Ind. Electron., vol. 62, no. 3, 683 Mar. 2015

684 [18] E. Fournier et al., "Current-based detection of mechanical unbalance in fault detection in permanent-magnet multiphase machines," IEEE Trans. 697 Ind. Electron., vol. 62, no. 3, Mar. 2015.

[22] B. Aubert, J. Régnier, S. Caux, and D. Alejo, "Kalman-filter-based in- 699 dicator for online interturn short circuits detection in permanent-magnet 700 synchronous generators," IEEE Trans. Ind. Electron., vol. 62, no. 3, 701 Mar. 2015

[23] S. M. Mirimani, A. Vahedi, F. Marignetti, and R. Di Stefano, "An online 703 method for static eccentricity fault detection in axial flux machines," IEEE 704 Trans. Ind. Electron., vol. 62, no. 3, Mar. 2015.

[24] C. Chakraborty and V. Verma, "Speed and current sensor fault detection 706 and isolation technique for induction motor drive using axes transforma- 707 tion," IEEE Trans. Ind. Electron., vol. 62, no. 3, Mar. 2015.

[25] J. G. Norniella et al., "Coupling inductor fault detection and estimation 709 in three-phase adjustable-speed drives with direct power control-based 710 active front-end rectifiers," IEEE Trans. Ind. Electron., vol. 62, no. 3, 711 Mar. 2015.

[26] C. Choi, K. Lee, and W. Lee, "Observer-based phase-shift fault detection 713 using adaptive threshold for rotor position sensor of permanent-magnet 714 synchronous machine drives in electromechanical brake," IEEE Trans. 715 Ind. Electron., vol. 62, no. 3, Mar. 2015.

716

[27] M. A. Rodríguez-Blanco et al., "Fault detection for IGBT using adap- 717 tive thresholds during the turn-on transient," IEEE Trans. Ind. Electron., 718 vol. 62 , no. 3, Mar. 2015

[28] A. Stabile, J. O. Estima, C. Boccaletti, and A. J. Marques Cardoso, 720 "Converter power loss analysis in a fault-tolerant permanent-magnet 721 synchronous motor drive," IEEE Trans. Ind. Electron., vol. 62, no. 3, 722 Mar. 2015.

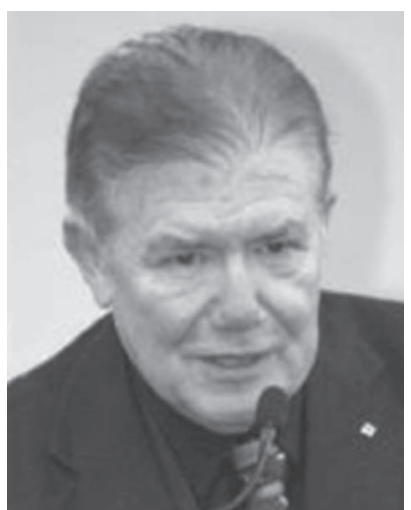

Gérard-André Capolino (A'77-M'82-SM'89-F'02) was born in Marseille, France. He 724 received the B.Sc. degree in electrical engineering from the Ecole Centrale de Marseille, 725 Marseille, in 1974, the M.Sc. degree from the Ecole Supérieure d'Electricité, Paris, 726 France, in 1975, the Ph.D. degree from the Aix-Marseille University, Marseille, in 1978, 727 and the D.Sc. degree from the Institut Polytechnique de Grenoble, Grenoble, France, 728 in 1987.

In 1994, he joined the University of Picardie "Jules Verne," Amiens, France, where he 730 is currently a Chair Professor of electrical engineering.

Dr. Capolino is an Associate Editor of the IEEE Transactions on POWER ELEC- 732 TRONICS, IEEE TRANSACTIONS ON INDUSTRIAL ELECTRONICS, and IEEE ACCESS. He 733 is also the acting Chair for the Steering Committee of the International Conference on 734 Electrical Machines (ICEM). He was the recipient of the 2008 IEEE-IES Dr.-Ing. Eugene 735 Mittelmann Achievement Award, the 2010 ICEM Arthur Ellison Achievement Award, and 736 the 2011 IEEE-PELS Diagnostics Achievement Award.

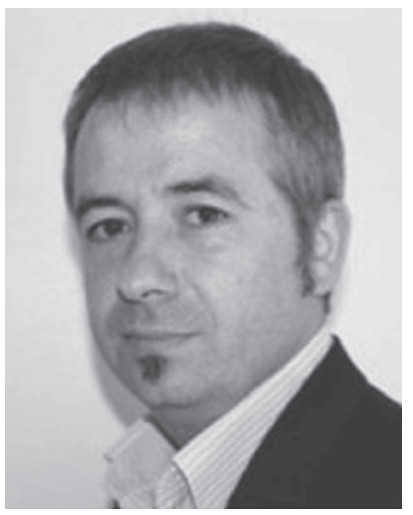

Jose A. Antonino-Daviu (M'06-SM'12) received the M.Sc. and Ph.D. degrees in 738 electrical engineering from the Universitat Politècnica de València, Valencia, Spain, in 739 2000 and 2006, respectively.

He worked in the private sector, having been involved in several international projects. 741 Currently, he is an Associate Professor with the School of Industrial Engineering, 742 Universitat Politècnica de València. His primary research interests include condition 743 monitoring of electric machines, wavelet theory and its application to fault diagnosis, 744 and design and optimization of electrical installations and systems. 


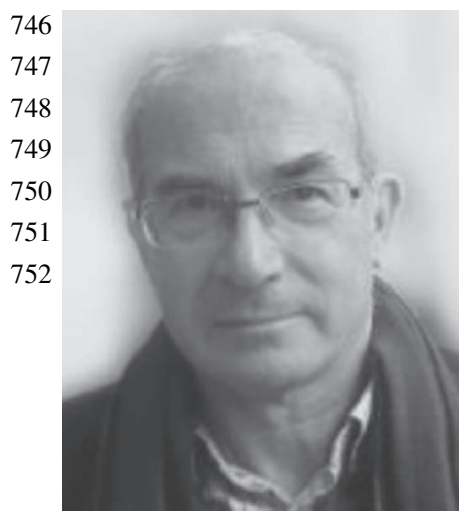

Martin Riera-Guasp (M'94-SM'12) received the M.Sc. degree in industrial engineering and the Ph.D. degree in electrical engineering from the Universitat Politècnica de València, Valencia, Spain, in 1981 and 1987, respectively.

Currently, he is an Associate Professor with the Department of Electrical Engineering, Universitat Politècnica de València. His research interests include condition monitoring of electrical machines, applications of signal analysis techniques to electrical engineering, and efficiency in electric power applications. 


\section{AUTHOR QUERIES}

\section{AUTHOR PLEASE ANSWER ALL QUERIES}

AQ1 = Please check if provided definition for DSP is correct. Otherwise, please make the necessary corrections.

AQ2 = Please check if provided definition for MCSA is correct. Otherwise, please make the necessary corrections.

END OF ALL QUERIES 